\title{
Not just the bus: an approach to extend dialogue marketing
}

\author{
C. Link, R. Hössinger, U. Raich \& W. Unbehaun \\ Institute for Transport Studies, \\ University of Natural Resources and Life Science, Vienna, Austria
}

\begin{abstract}
Even where the level of public transport (PT) services is of sufficient quality, mobility behaviour is often characterized by intensive car use. The most frequently stated subjective reasons not to use PT can be summarized in two main aspects: a paucity of information concerning PT services, and subjective constraints to its use. Various soft transport policy measures of which dialogue marketing might be the most popular one address these problems. Although the general concept of dialogue marketing is sound and thoroughly tested, need for additional research exists in different terms. Among others, shortcomings of dialogue marketing campaigns (DMC) are: (i) they are always focused on one topic like mobility behaviour or waste prevention; (ii) most application areas have a high population density and thus a good PT accessibility, and (iii) impact stability over time is rarely analyzed. A DMC considering these aspects was conducted within a research project. It can be shown, that (i) an interdisciplinary marketing campaign covering energy use and mobility behaviour achieves sufficient results; (ii) the marketing approach works better in areas with a good PT accessibility, and that (iii) behavioural changes can be identified one year after the dialog marketing campaign was conducted.

Keywords: dialogue marketing, interdisciplinary approach, impact stability, mobility behaviour, soft transport policy measure.
\end{abstract}

\section{Dialogue marketing}

There are good arguments to avoid car traffic. The maybe most frequently used refers to road transports' impacts on climate: in 2010 27\% of the total Austrian GHG emissions stem from the transport sector with passenger road transport as 
the most important emitter by far (UBA [1]). However, also other aspects call for a reduction of car traffic such as the space requirements for parking and driving, emissions as noise and stench, the accident rate or landscape dissection. Strategies pointing on avoiding car trips can be distinguished in hard and soft transport policy measures. All attempts to promote voluntary behavioural changes are referred to as "soft" measures (Bamberg et al. [2], Cairns et al. [3]).

Some trips have to be made by car - either because no alternative means of transport are available or persons or heavy goods have to be transported. For all other trips, car use is more or less mandatory. This applies to approximately every second car trip (Brög [4]). However, within the German national mobility survey "Mobility in Deutschland", $42 \%$ of the respondents stated to use public transport never or at least almost never (Vortisch et al. [5]). Frequently used reasons not to use PT are general preferences for other modes, security concerns, an insufficient level of PT services, high fares, inadequate comfort, missing information, and its image (Beirao and Cabral [7], Stradling et al. [6]). Some of these reasons can be summarized as subjective constraints to PT use. Concerning other aspects - namely fares, level of services, and security concerns - it is questionable whether or not they are objectively justified. It can be assumed, that some of the supposed problems are prejudices resulting from poor information on PT services.

Soft transport policy measures are aiming on overcoming subjective constraints, raising the level on information concerning PT and creating positive images. Cairns et al. [3] distinguish between ten different kinds of soft measures. However, the boarders between these categories are partly blurring. Examples are personalized travel planning, travel awareness campaigns, and public transport information and marketing - that have close similarities in their practical implementation. At least, if they are taken as one, they are the probably most often used soft policy measure (Möser and Bamberg [8]). We refer to this kind of soft transport policy measure as dialogue marketing.

Dialogue marketing is a multi-step marketing approach aiming on changes in mobility behaviour. It is characterized by a repeated, intensive and demandorientated communication process between PT operators and their actual and potential customers. It seeks to overcome both, a lack of information concerning existing PT services and subjective constraints to their use. For this reason, both, individualized as well as general information material is delivered to the participants depending on their information needs. Additionally, an intensive communication process is started providing personal advisory services (Brög et al. [9]). One central aspect of the approach is to focus all efforts on the most promising persons in terms of mobility behaviour changes. These are nonfrequent PT users with an insufficient level of information on PT services or other constraints towards their use. This clearly-focused strategy makes this approach more effective than other marketing measures (Brög [4]). By showing that PT services are better than assumed to be, participants are motivated to voluntary change their mobility behaviour (Cairns et al. [3]). Up to now, dialog marketing campaigns in transport sector have been applied all over Europe, 
e.g. in Austria (Waldhör et al. [10]), Germany (Ker [11]), Great Britain (Cairns et al. [3]) or Spain (Ker [11]).

A continuing methodological development of the approach can be identified. While former campaigns focus strictly on public transport, new approaches include all eco-modes of mobility such as walking and cycling. This makes particularly sense from an overall, sustainable point of view; from the participant's point of view the credibility of the approach increases. As a consequence, these kind of DMCs outperform traditional DMCs also in terms of the number persons attracted by PT (Brög et al. [9]). However, public transport remains the core of dialogue marketing, as certain car trips can often only be replaced by public transport.

DMCs have a clear positive effect with 15 up to 40 additional PT trips per person and year - with a higher percentage increase in areas with a belowaverage PT use (Ker [11]). Cairns et al. [3] indicate reductions amounting for $7-15 \%$ of car driver trips. DMCs are particularly successful if they are conducted in combination with infrastructural improvements (Ker [11]). The various results stated in literature are consistent to a degree that Möser and Bamberg [8] assume either dialogue marketing to be an extremely successful approach or some kind of publication bias is present.

The general concept of dialogue marketing can be assessed as sound and thoroughly tested. However, further possibilities to extend or improve this instrument are discussed in literature. They are presented in the following chapter. Within a research project several of these extensions were applied. Some of them are presented in this paper. They are evaluated by both, performance and output indicators. Performance indicators refer to the implementation of the DMC, output indicators on behavioural changes achieved.

\section{Extensions of the dialogue marketing}

Several authors argue that sound knowledge on several aspects of the dialogue marketing approach is still missing. This applies to

Interdisciplinary approach: DMCs have just one topic like mobility behaviour or waste prevention. However, some authors assume that considerable synergy effects could be achieved by an approach combining different topics in interdisciplinary campaigns - at least if they address the same target group. Accompanying topics to mobility could be in principal all topics affecting daily such as water or energy savings as well as waste prevention or even shopping behaviour (Heller [12]).

Application area: Most DMCs were conducted in urban areas with an aboveaverage level of PT services. Campaigns in suburban or even rural areas were made only in a few exceptions. Thus knowledge is missing on the effectiveness of the approach in areas with a suboptimal PT availability (Richter et al. [13]).

Impact stability over time: Only little empirical findings exist with regard to long-term changes in mobility behaviour covering at least a period of six month (Cairns et al. [3]). Thus, there are uncertainties concerning the stability of the 
achieved impacts. Some authors argue that the impacts are, due to the "voluntary nature" of the measure, constant over time (Brög [4]).

Overall impact assessment: Several positive side effects can be expected by a mode shift from car to more sustainable modes; to make a trip by bus or by feet is cleaner, saver, and more healthy. However, these effects are often not valued. From this raises the question of an overall assessment of all impacts of dialogue marketing. In particular, cost-benefit-analyses - also including environmental or health issues - are missing (Richter et al. [13]).

\section{Research project DIALOG}

These four extensions of a DMC - interdisciplinary approach, application area, impact stability and overall assessment - were subject of the research project DIALOG (Individual motivation for climate-friendly energy use in transport and household). It was conducted by the Institute for Transport Studies, University of Natural Resources and Life Science, Vienna, Austria and Socialdata GmbH between 2009 and 2012, founded by the Austrian Climate and Energy Fund within the program "New Energies 2020". The research design included a standard dialogue marketing approach that was extended in several ways. Three of these extensions are treated in this paper.

Interdisciplinary approach: The mobility campaign was extended by a second topic. Precondition for its selection was (i) climate relevance, and (ii) that daily behaviour of households is concerned. We decided for an interdisciplinary campaign combining mobility behaviour and energy use. Decisive for the selection of the topic of energy use were two aspects. First, it is of high relevance for the reduction of GHG-emissions; households' room heating accounts for approximately $13 \%$ of total Austrian GHG-emissions, further emissions result from electric energy consumption (UBA [1]). Second, private households can reduce GHG-emissions by behavioural or attitudinal adaptations.

Application area: To analyze the impact of spatial patterns and PT availability on the effectiveness of the approach, we selected three application areas. They differ in terms of their spatial structure. One was in a suburban area (municipality Ottensheim, agglomeration of Linz), and two in more or less urban parts of the major Austrian cities Linz, and Graz.

Impact stability over time: A multi-wave panel-survey on mobility behaviour and energy use was conducted. As the second wave was conducted 6-7 months after the DMC and the third one 16 months, we were able to analyze short- and long-term impacts.

\subsection{Dialogue marketing campaign conducted within DIALOG}

The objective of DIALOG was to break new ground in realms of these four aspects. Thus we avoided to apply further process innovations such as the integration of participative elements or social media. Instead we applied a classical multi-step dialogue marketing approach (Brög [4]): 
(1) Contact stage: Randomly chosen persons were contacted using a cover letter and asked for participation. Afterwards, households with known telephone number were called, the other were visited at home. They were asked for both, information demand, and travel behaviour.

(2) Segmentation stage: According to their information demand as well as their mobility behaviour, people were divided into groups. Within the mobility marketing, all households that stated (i) to have information needs, and (ii) to use PT seldom or never, were invited to participate in the DMC.

(3) Encouragement stage: Households without information needs and sustainable mobility behaviour were encouraged in their behaviour by a small gift.

(4) Motivation stage: A register listing general information materials and small gifts was sent to the participants. Additionally, individualized information materials such as personal schedules were offered. Participants selected all the information they are interested in. They were also able to denote a need for personal consultancy.

(5) Information stage: The chosen material was handed out personally by trained personal. The delivery was executed by employees of the public transport operators, energy suppliers and staff of the project team.

(6) Conviction stage: Personal consultancy was conducted.

The mobility campaign was conducted from May to July 2010. It included all eco-modes of mobility, not only public transport. The energy campaign was twofold; one part aimed on reducing energy consumption by attitudinal and behavioural changes. Target group were all households living in the application areas representing all urban and suburban areas. The second part concerned energetic building refurbishment. As only owner-occupiers of flats or houses have the opportunity to implement such measures, only those belonged to the target group. Owner-occupiers were recruited from the pool of all participants on the energy dialogue marketing. The campaign on energy use was conducted in October and November 2010.

To limit costs and organizational efforts, available information materials of the PT operators and energy suppliers were used. These general materials were supplemented by individualized information materials. They were produced for each participant, if required. Additionally, some gifts were prepared. They were used to increase customer loyalty for current PT users, and to enhance willingness to participate in the dialogue marketing. Gifts were intended to have a connection to mobility or energy use.

For the mobility related dialogue marketing campaign, for each of the application areas in Graz and Linz 17 general information materials concerning different aspects of mobility behaviour were collected, and 25 for suburban Ottensheim. Individualized information materials included personal timetables or travel cost information. Examples for the gifts offered were rebate vouchers for bicycle repair, pedometers or nightlights for bicycles and pedestrians. For the conviction stage, free PT-tickets valid for a week or a month were made available by local PT operators. 


\subsection{Evaluation concept applied within DIALOG}

To measure the impacts both campaigns a standardised survey was conducted. Additionally, the energy consumption was evaluated by measurement figures of energy consumption made available by an energy supplier. The panel survey was conducted in three waves to analyze short- and long-term impacts. The first survey aiming to capture the behaviour in status quo for all members of the household was conducted at the beginning of the mobility campaign in spring 2010, respectively at the beginning of the energy use campaign in autumn 2010. The second wave was conducted for both, the mobility and the energy use campaigns in the very beginning of 2011. Aim of this wave, was to measure the short term effects directly after the completion of campaigns. The last wave allowing the assessment of impact stability over time took place in autumn 2011. For all survey waves a set of equal behaviour-related questions added by some wave specific questions was used. It allows a longitudinal comparison of behaviour corresponding to a panel survey. In the second and third wave questions on the perception of the marketing campaign and on the perception of the respondents mobility behaviour were asked like "Have you talked with your family, colleagues or friends about the campaign?" or "Do you feel better informed about mobility options?”.

The survey had to hold a thin line between two aspects; on the one hand to gather data for the evaluation as detailed as possible; on the other hand to motivate the participants to join the campaigns and not to limit their willingness to participate by fatiguing respondents. In other words, there is a trade-off between evaluation accuracy and participation rate.

Another aspect had to be considered. Within the DMC general information material was used. All members of a participating household were able to read it; it can be expected that sustainable mobility behaviour was subject of conversations within the family once the campaign started. Thus, all household members might adapt their mobility behaviour; so the evaluation had to include all household members.

For these reasons we decided for a telephone survey with easy to answer questions. In the survey for the mobility campaign, the person who answered the phone call was asked to report the mobility behaviour of all household members. The questions covered (i) the availability of PT season ticket in the household and the number of days with (ii) PT use, (iii) car use, or (iv) with walking trips within the last week. If the mode was not used within this period of time, the reference period was extended on the last month. The interview of the survey on energy use consisted of a set of six questions on the practiced energy use concerning e.g., room temperature during winter season or use of green energy. These answers were gathered once per household. Concerning building refurbishments, owner-occupiers were asked, whether or not there is a potential for energetic sanitations in the field of insulation, heating, or water heater and they intend to invest in one of these fields.

This procedure allows for quick answers providing a sufficient level of information to make general statements. However, a modal split cannot be 
calculated; additionally, it cannot be clearly stated whether an increase in the number of days using a certain mode is due to additional trips or due to a more intermodal mobility behaviour. For cost reasons a survey with a control group was not possible. The data collected were checked for plausibility. Afterwards the data were analyzed by means of descriptive statistics and comparisons of means for dependent samples ( $\mathrm{t}$ tests).

\section{Results}

\subsection{Performance indicators}

Performance indicators describe important features of the dialogue marketing procedure without elaborating possible behavioural changes. The gross sample for the mobility DMC consisted of 2,997 households. 561 belonged to the quality neutral sample losses (incorrect address data, several unsuccessful contact attempts, etc.). From the adjusted gross sample of 2,436 households, 1,640 did not reject their participation. Not all of them ordered information materials; some of them who did, have no information needs. In the end, $42 \%$ of the adjusted gross sample has ordered materials.

Households living in Ottensheim have ordered eleven information materials in average; in Graz ten and in Linz six materials were requested. There is no clear tendency concerning the kinds of material most often ordered. General information on regional sightseeing or hiking tours was ordered often. For example, the brochure "City hiking tours in Linz" was ordered by almost 50\% of households living in Linz, and 58\% in Ottensheim. While this information is leisure-oriented, also information on public transport was often requested. In the "timetable book Linz" more than $40 \%$ of participants in Linz and Ottensheim were interested in. The folder "public transport network Graz" was requested by $45 \%$ of the participants in Graz. These numbers clearly show the existing demand for information summarizing existing knowledge: obviously a lot of people do not use the manifold opportunities to inform about sustainable mobility on their own.

\subsection{Short-term impacts on mobility behaviour}

Mobility behaviour was analyzed in a panel design for all persons that have participated in the DMC and at least in one of the two survey waves. Within the second survey wave mobility data for 748 to 780 persons were recorded - the number differs depending on the mode (Table 1). The short term analysis shows the impact intended by the DMC. The number of days with walking or PT trips increases significantly, while the number of car driver trips decreases. However, the intensity of changes varies widely: The number of days with walking trips rose by more than two days $(+18.2 \%)$, while the increase in the number of days with PT use just raised for $8.3 \%$. On the other hand, the number of days with car driver trips decreases slightly. 
Table 1: Mobility behavior of participants on the first and second survey wave.

\begin{tabular}{lccccc}
\hline \multicolumn{5}{c}{ Days with trips within the last month } \\
Mode & $\begin{array}{c}\mathrm{n} \\
\text { [persons] }\end{array}$ & $\begin{array}{c}\text { Status quo [days/4 } \\
\text { weeks] }\end{array}$ & $\begin{array}{c}\text { Short-term [days/4 } \\
\text { weeks] }\end{array}$ & $\begin{array}{c}\text { Percentage } \\
\text { change }\end{array}$ & p-Value \\
\hline PT & 748 & 8.1 & 8.8 & $+8.3 \%$ & $\mathrm{p}<0.01$ \\
\hline Walking & 754 & 13.3 & 15.6 & $+18.2 \%$ & $\mathrm{p}<0.01$ \\
\hline Car driver & 780 & 8.8 & 8.7 & $-1.4 \%$ & $\mathrm{p}=0.50$ \\
\hline
\end{tabular}

The meaning of the indicator "days with mode use within the last month" should not be overemphasized. It is more or less a soft indicator. For example, the increase in $8.3 \%$ of days with PT use does not necessarily mean that the number of PT trips rises to the same extent. Keeping this in mind, this indicator allows showing changes in preferences for single modes. Within the short-term perspective, there are impressive gains in both eco-modes of mobility.

\subsection{Impact stability over time: Long-term impacts}

Impact stability over time can be assessed by comparing the mobility pattern stated in the third survey wave with behaviour stated in the first two surveys. As only persons who attended the second survey were contacted within the third survey, the participants' number decreases from the second to the third survey (Table 2).

Within the long-term perspective substantially different impacts can be shown for walking and PT use on the one hand and car trips as driver on the other hand (Table 2). For days with car driver trips, a steady but small decrease can be measured over the three surveys. In the long-term perspective, the days with car trips as driver decrease for two percent compared to the status quo. Contrary, both eco-modes of mobility have a peak in the number of days per month in the short-term view. Compared to the situation previous to the dialogue marketing, the number of days with both, walking and PT trips is significantly higher in the long-term perspective. However, the resulting status is below the short-term changes.

Table 2: Mobility behavior of the participants on all three survey wave

\begin{tabular}{|c|c|c|c|c|c|c|}
\hline \multirow[b]{2}{*}{ Mode } & \multirow[b]{2}{*}{$\begin{array}{c}\mathrm{n} \\
\text { [persons] }\end{array}$} & \multicolumn{3}{|c|}{$\begin{array}{l}\text { Days with trips within the last month } \\
\text { [days/4 weeks] }\end{array}$} & \multicolumn{2}{|c|}{$\begin{array}{c}\text { Comparison: } \\
\text { Status quo to long-term }\end{array}$} \\
\hline & & Status quo & Short-term & Long-term & $\begin{array}{l}\text { Percentage } \\
\text { change }\end{array}$ & p-Value \\
\hline PT & 563 & 7.7 & 8.7 & 8.2 & $+6.0 \%$ & $p=0.04$ \\
\hline Walking & 570 & 13.2 & 15.8 & 14.0 & $+6.3 \%$ & $p<0.01$ \\
\hline $\begin{array}{l}\text { Car } \\
\text { driver }\end{array}$ & 596 & 9.5 & 9.4 & 9.3 & $-2.0 \%$ & $p=0.37$ \\
\hline
\end{tabular}

In the short-term perspective, people adapt their behaviour. In the course of time, some people return to their former routine. This can be due to a loss in the convincing power of the incentives, or as the known behaviour might have objective or subjective advantages. Despite to this fact, clear stability of the DMC's impacts over time can be shown. 
From the survey design raises a risk of (self-) selection biases concerning the participation rate. Such effects are present, but limited in their extent; persons taking part in all three surveys are using PT less frequently previous to the DMC than those participating only in the first two surveys. This also refers to walking trips, while the number of car trips is significantly higher $(p=0.02)$. The percentage changes in mobility behaviour are identical in the short-term perspective for both groups for car use, while the increase in both eco-modes of travel is slightly higher for the participants on all three survey waves. However, differences are limited and not significant. Thus self-selection processes with regard to the perception of the DMC are not present.

\subsection{Spatial effectiveness}

Within the study at hand three different application areas were selected with two of them having an urban, and one suburban character. The comparison of their results allows assessing the spatial impact on the effectiveness of the approach. Unfortunately, a separated output analysis for the application area in Linz - that is in terms of its PT accessibility and degree of urbanity between the application area in Graz and the suburban Ottensheim - is not meaningful due to the limited number of participants. Thus just Graz and Ottensheim can be compared.

Performance: Within the suburban Ottensheim, the share of people willing to participate in the DMC is $86 \%$ of the adjusted gross sample; this is above the average value of $67 \%$. Contrary, the share of households with information needs is below average in Ottensheim. From these two effects - the willingness to participate and the information needs - results the final participation rate: information materials were delivered to $48 \%$ of households living in Ottensheim; that is six percentage points above average. The number of household members participating in Graz is between 297 (for PT use) and 308 (car drivers), while it is between 199 and 220 in Ottensheim.

Output: The number of days with car driver trips previous to the DMC is higher in Ottensheim than in Graz (10.5 to 9.4), while PT is used more rarely (5.5 to 8.7). The number of walking trips is nearly the same. Concerning the behavioural impacts on eco-modes of mobility, the pattern known from the total sample can be found in both areas. In the short-term, there is a clear increase in the number of days with both, walking and PT trips. The differences between both areas are not significant at a 5\%-level for walking trips, while there is a significant higher increase in PT use in Graz $(\mathrm{p}=0.04)$. The status achieved in the long-term perspective is below that maximum, but exceeds the status quo. In the long-term perspective, the increase in PT use days within the last month is $6.0 \%$ for Graz, and 3.8\% for Ottensheim, while the increase in walking days is equal (5.0\% in Graz, 5.2\% in Ottensheim). These differences are not significant.

Concerning car use, there are no clear results. For Graz, there is a high decrease in the number of days with car use as driver for $13.2 \%$ in the long-term, while days with car use increase in Ottensheim for $7.2 \%$. This difference is highly significant $(\mathrm{p}<0.01)$. This also refers to the short-term perspective. However, the result achieved in Ottensheim with an increase in days with car use in both, short- and long-term perspective seems implausible. 


\subsection{Impacts on energy use}

In four of the six indicators describing sustainable energy use, environmental friendly behaviour is more common in the short- and long-term perspective. This refers e.g. to the use of green electricity or to pay attention on energy class when buying electric devices. Due to the limited number of households with valid answers (56-163 households), a significant impact cannot be identified. The survey also addressed energetic building refurbishments. The number of owneroccupiers considering refurbishments with regard to insulation, heating or water heating as promising is more than doubling in the long-term perspective. The increase in the number of owner-occupiers with concrete intentions to invest in these fields is even higher.

For the suburban area of Ottensheim, changes in energy use could also be identified by measurement figures of energy consumption for both, electrical devices and water heating. Energy consumption between 2009 - the year previous to the dialogue marketing - and 2011 is objectively comparable in this way; the energy consumption of the households participating in the DMC was compared to those of a control group of all private households living in comparable quarters in Ottensheim. The group of participants decreased their energy use for $3.7 \%$ for electrical devices, and $5.0 \%$ for water heating. The changes of the control group account for just $1.9 \%$, and $1.2 \%$ respectively. GHG-emissions reduction may result from the extended use of green energy.

\subsection{Synergy impacts due to the interdisciplinary campaign}

Is it better to conduct an interdisciplinary DMC covering more than one topic instead of separated campaigns? The answer to this question is twofold; it concerns expenses and organizational efforts as well as behavioural changes achieved.

Additional expenses of an interdisciplinary campaign compared to a one-topic campaign appear as the number of local partners such as PT operators, energy suppliers and local authorities to be involved, increases. Within the study at hand local partners for two topics and three areas had to be identified, contacted and supervised. There are approximately no decreasing marginal costs when integrating an additional partner in terms of the workload; this may collide with the often small limits of the window of time for preparing and conducting the campaign; thus, in a time with an already high workload, an interdisciplinary campaign causes additional organizational and time costs.

Within our evaluation concept based on three survey waves, a combined campaign has significant advantages. Households contacted within the telephone survey were asked some additional questions compared to the situation of separated campaigns. As some households only took part in one campaign, we can compare the average duration of a phone call to evaluate both or just one campaign: within the third survey wave a phone call within the energy-campaign accounts for 354 seconds in average, to assess only the mobility campaign needs 357 seconds, and to evaluate both campaigns in one call 441 seconds. 


\section{Conclusion}

Dialogue marketing allows overcoming both, information lacks concerning PT services and other eco-modes like walking and cycling as well as subjective constraints to use them. This is done by providing information material and personal consultancies based on the individual demands. The research project DIALOG contributed to the further development of this approach by analysing the impact of certain extensions. This refers to an interdisciplinary approach including energy use and mobility, as well impact stability over time and the impact of spatial patterns on the effectiveness of the approach.

Within a short-term perspective, the number of days with PT use and walking trips increases significantly, while the number of days with car driver trips decreases slightly. The identified impacts are smaller than those denoted in literature, for example for application sites in Japan (days with PT use: +38.6\%) (Taniguchi et al. [14]), Sweden (+0.7 days with PT use per person and week) (Friman et al. [15]) or Germany (+28 days with PT use per person and year) (Brög et al. [9]). Also for Austria higher impacts are stated; for a campaign conducted in the city of Linz, the increase in PT use accounts for 13\% (Waldhör et al. [10]). However, we assess the increase of 0.7 days with PT use per person and month in the short-term perspective to be quite impressive.

While short-term impacts are analyzed quite often, only little empirical evidences exist for the stability of achieved impacts over time. High impact stability within a time period of two years can be shown for an application area in Dalvik, Sveden (Brög et al. [9]). It is argued, that due to the voluntary character of the measure the impact stability should be high. This finding can only be confirmed to some extent. The impacts identified in our study are stable over time in the way that significant behavioural changes for PT and walking can be identified one year after the conduction of the DMC. However, there is a loss in impact power compared to the peak situation half a year after the conduction of the marketing campaign. It cannot finally be clarified, whether this decrease in impact power continues or a final level is already reached. Thus, an additional survey would make sense.

The analysis of spatial impacts on the effectiveness of the approach has no clear result. The willingness to participate in the dialogue marketing for mobility is higher in the suburban area of Ottensheim. However, a sufficient level can be reached in all areas. Concerning behavioural changes, the null hypotheses, that spatial patterns and PT accessibility have no influence on the output of the dialogue marketing in the long-term perspective cannot be rejected. Even if the DMC performs slightly better in Graz compared to the other case studies, the differences are not sufficient powerful. However, in the short-term, there are significant differences for PT use with a better result in the urban area of Graz. This does also apply to car driver trips; significant differences can be identified.

The intended results could also be achieved within the energy related marketing campaign. Both, the survey on energy use and the more objective analysis of measurement figures of energy consumption reveal an increase of sustainable behaviour. However, the question of whether or not an 
interdisciplinary approach makes sense cannot purely be answered by behavioural changes. Instead it has to be shown where synergy effects can be achieved. Within the project DIALOG, synergy effects were achieved in particular when evaluating the survey waves. Time needed for a phone call to evaluate two separated campaigns is $64 \%$ higher than in a common, interdisciplinary campaign.

\section{References}

[1] UBA Umweltbundesamt, Klimaschutzbericht 2012, 2012.

[2] Bamberg, S., Fujii, S., Friman, M., Gärling, T., Behaviour theory and soft transport policy measures, Transport Policy, 18, pp. 228-235, 2011.

[3] Cairns, S., Sloman, L., Newson, C., Anable, J., Kirkbride, A., Goodwin, P., Smarter Choices: Changing the Way We Travel, 2004.

[4] Brög, W., Förderung nachhaltiger Nahmobilität durch bewusstseinsbildende Maßnahmen, 2008.

[5] Vortisch, P., Zumkeller, D., Chlond, B., Kagerbauer, M., Chlond, B., Streit, T., Deutsches Mobilitätspanel (MOP) wissenschaftliche Begleitung und erste Auswertungen. Bericht 2011: Alltagsmobilität \& Tankbuch, 2011.

[6] Stradling S., Carreno M., Rye T., Passenger perceptions and the ideal urban bus journey experience, Transport Policy, 14, 4, pp. 283-292, 2007.

[7] Beirao, G., Cabral, S., Understanding attitudes towards public transport and private car: A qualitative study, Transport Policy, 14, 6, pp. 478-489, 2007.

[8] Möser, G., Bamberg, S., The effectiveness of soft transport policy measures: A critical assessment and meta-analysis of empirical evidence, Journal of Environmental Psychology, 28, pp. 10-26, 2008.

[9] Brög, W., Erl, E., Ker, I., Ryle, J., Wall, R., Evaluation of voluntary travel behaviour change: Experiences from three continents. Transport Policy, 16, 6, pp. 281-292, 2009.

[10] Waldhör, A., Dietrich, K., Brög, W., Erl, E., Dialog- und Direktmarketing. Marketingvarianten im Vergleich, Der Nahverkehr, 10, pp. 55-60, 2009.

[11] Ker, I., Travel Demand Management: Public Transport Business Case, 2003.

[12] Heller, J., Gewinnen und Binden von Fahrgästen durch Direktmarketing, HKV - Handbuch der kommunalen Verkehrsplanung, 2003.

[13] Richter, J., Friman, M., Gärling, T., Soft transport policy measures 2: Research needs, 2009.

[14] Taniguchi, A., Suzuki, H., Fujii, S., Mobility management in Japan: its development and meta-analysis of travel feedback programs, Transportation Research Record 2021. 2007.

[15] Friman M., Larhult L., Gärling, T., An analysis of soft transport policy measures implemented in Sweden to reduce private car use, Transportation. Issue May, 2012. 